\title{
Reconhecer os alunos para reinventar a escola: da afirmação de uma necessidade aos equívocos de um desejo
}

Rui Trindade

Universidade do Porto

\begin{abstract}
Resumo
O Movimento da Escola Moderna Portuguesa - MEM - constitui-se, neste artigo, como um objecto de reflexão teórica cuja pertinência deriva da necessidade de se reflectir, por meio desse movimento, os propósitos, as reivindicações e os sentidos dos projectos de mediação curricular e didáctica de todos aqueles que reivindicam, de forma explícita, o seu distanciamento conceptual e praxeológico face ao campo das pedagogias da instrução. É tendo em vista esse propósito que se começa por identificar os eixos estruturantes do campo das pedagogias da aprendizagem a partir da leitura das obras de alguns dos pedagogos mais emblemáticos do Movimento da Educação Nova, confrontando-os, posteriormente, com o legado pedagógico do MEM, de forma a poderem interpelar-se, num primeiro momento, as zonas de luz e de sombra que atravessam, hoje, os discursos pedagógicos, curriculares e didácticos que reivindicam a sua pertença ao campo atrás referenciado e, num segundo momento, a reflectir-se sobre as respostas que no seio do MEM se foram construindo, de forma a cumprirem-se os desígnios de um projecto educacional que se caracteriza por valorizar os alunos como interlocutores e produtores de cultura.
\end{abstract}

Palavras-chave

Aprendizagem - Mediações didácticas - Pedagogia da comunicação.

\section{Correspondência}

Rui Trindade

Fac. de Psicologia e de Ciências da

Educação

Universidade do Porto

Rua Dr. Manuel Pereira da Silva

4200-392 - Porto - PORTUGAL

e-mail: trindade@fpce.up.pt 


\title{
Recognizing the students in order to reinvent the school: from the affirmation of a need to the misleads of a desire
}

Rui Trindade

Universidade do Porto

\begin{abstract}
In this article, the Portuguese Modern School Movement (MEM) constitutes an object of theoretical reflection, its pertinence deriving from the need to reflect, by means of this movement, upon the goals, the demands and the meaning of educational and curricular mediation projects of all those who explicitly claim their praxological and conceptual separation from the field of instruction pedagogies. With such purpose in mind, we start by identifying the main principles in the field of pedagogies of learning by reading the works of some of the most emblematic pedagogues of the New Education Movement, and we proceed by contrasting them with the MEM pedagogical legacy. As a result, in a first instance, we can expose the current areas of light and shadow crossed by educational, curricular and pedagogical discourses that allegedly belong to the field of pedagogies of learning, and secondly we can reflect upon the adjustments developed within MEM in order to meet the objectives of an educational project characterized by recognizing students as mediators and producers of culture.
\end{abstract}

\section{Keywords}

Learning - Educational mediation - Pedagogy of communication. 
Neste artigo, visa promover-se um confronto entre o património pedagógico e didáctico do Movimento da Escola Moderna Portuguesa MEM - com os pressupostos e os propósitos que sustentam a afirmação e o desenvolvimento do campo que podemos designar como o das pedagogias da aprendizagem (Altet, 1999). 0 que se pretende, como finalidade última dessa reflexão, é, afinal, abordar até que ponto esse património permitiu superar alguns dos eventuais equívocos, contradições e ambiguidades desse campo a partir do legado do Movimento da Educação Nova ${ }^{1}$ em função do qual aquele campo foi sendo erigido.

A importância do MEM como movimento pedagógico influente pode ser compreendida, num primeiro momento, por declarações de académicos tão respeitados como Albano Estrela (1992) - "tem sido em Portugal a organização mais coerente na formação de professores" (p. 19) - ou António Nóvoa (1992) - "eles [os associados do MEM] são portadores do que há de melhor na pedagogia portuguesa" (p. 26). Trata-se de afirmações que corroboram a intensa actividade de associados do movimento em iniciativas pedagógicas no seio do sistema educativo português como, por exemplo, a participação em grupos de trabalho relacionados com o $1^{\circ}$ Ciclo do Ensino Básico que o Departamento de Educação Básica do Ministério da Educação promoveu; a participação no organismo estatal responsável, em Portugal, pela formação contínua de professores (Conselho Científico-Pedagógico da Formação Contínua); a participação na produção de materiais de apoio aos novos programas do $1^{\circ}$ Ciclo e às novas orientações curriculares da Educação Pré-Escolar; a colaboração na revisão dos currículos nacionais desse $1^{\circ} \mathrm{Ciclo}$; a consultadoria prestada à Inspecção-Geral de Ensino ou, entre outras, o contributo público no âmbito das discussões e reflexões relacionadas com a construção de uma escola mais inclusiva.

A opção por eleger o património pedagógico e didáctico do MEM como instrumento de interpelação não aconteceu por acaso ou de forma arbitrária. Em primeiro lugar, esse é um movimento pedagógico que se enquadra, tal como o já referido Movimento da Educação Nova, num campo educativo onde se visa construir um paradigma pedagógico alternativo àquele que as pedagogias da instrução configuraram. Em segundo lugar, o MEM, como associação pedagógica, tem uma existência activa e reconhecida, na sociedade portuguesa, há mais de 30 anos, disponibilizando, por isso ou em função disso, de um património rico, diversificado e pertinente que poderá ser entendido como um património de referência em função do qual podemos interpelar quer o Movimento da Educação Nova, quer o próprio campo das pedagogias da aprendizagem, tanto do ponto de vista das suas potencialidades, como das suas vulnerabilidades. É, assim, tendo em conta essas duas propriedades que se justifica o papel que se atribui ao MEM neste artigo. Um papel em função do qual se constrói uma reflexão que se encontra organizada em duas partes: uma primeira onde se confere visibilidade às zonas de luz e sombra, no domínio da reflexão pedagógica e didáctica, dos discursos de alguns dos pedagogos mais emblemáticos que podem ser identificados com o Movimento da Educação Nova, de forma a identificarem-se as propriedades estruturantes do campo das pedagogias da aprendizagem; e uma segunda parte na qual se reflecte sobre os sentidos das propostas do MEM no domínio em causa, de forma a compreender-se até que ponto, e como, é que nesse movimento, por um lado, se foram confirmando, ignorando ou rejeitando os pressupostos e as respostas que alicerçam aquele mesmo campo e, por outro, quais as alternativas que, quer do ponto de vista conceptual, quer do ponto de vista da acção pedagógica e didáctica, se foram construindo no seio desse movimento.

Em última análise, o que se pretende é discutir se as implicações do reconhecimento

1. Movimento da Educação Nova será a designação, em língua portuguesa, que neste artigo se utilizará para me referir à Ligue Internationale pour l'Éducation Nouvelle e aos pedagogos que se relacionam ou são relacionados com o movimento pedagógico que esta constituiu. 
dos alunos como condição inegociável de um projecto de formação adequado aos desafios, às exigências e aos valores que balizam a vida em sociedades que se reivindicam como democráticas e que, simultaneamente, vivem processos de mutação económica e cultural inéditos, conduz-nos a entender os alunos como seres autossuficientes ou mesmo se é, só por si, o reconhecimento destes como actores educativos que poderá ser entendido como a pedra de toque de um tal projecto. Em suma, a questão que atravessa e determina este artigo é aquela por meio da qual se pergunta se o paradigma da aprendizagem é a alternativa ao paradigma pedagógico da instrução. Será, pois, essa a questão mais decisiva a que tentarei responder com a reflexão que me proponho realizar mediante a escrita deste texto.

\section{O Movimento da Educação Nova: zonas de luz e sombra de um projecto de reflexão pedagógica e didáctica}

Neste artigo, o Movimento da Educação Nova será abordado por via dos textos originais de alguns dos pedagogos que são identificados como referências maiores desse movimento. Tal como já se anunciou, pretende-se, por meio da leitura e da análise desses textos, identificar, num primeiro momento, o que poderão ser considerados os eixos invariantes do campo das pedagogias da aprendizagem para, num segundo momento, os interpelarmos e confrontarmos com os discursos que se têm vindo a construir no seio do MEM. Recorri, por isso, à leitura de textos da autoria de pedagogos tão prestigiados e reconhecidos como Adolphe Ferrière (1934) ${ }^{2}$, Édouard Claparède (1931; 1959; 1972) ${ }^{3}$, Maria Montessori ([s.d.]; 1958) ${ }^{4}$, Jean-Ovide Decroly $(1932 ; 1965)^{5}$, John Dewey (1963; 1966; 2002) ${ }^{6}$, Roger Cousinet (1945; 1959; 1978) ou Robert Dottrens (1974; 1974a; 1974b) para cumprir a primeira das finalidades enunciadas, e foi a partir dessa leitura que pude identificar aqueles eixos que, suportados por uma racionalidade pedagógica de tipo puerocêntrico, configuram um campo de preocupações educativas que, em larga medida, se define em função da valorização do acto de aprender em detrimento do acto de ensinar e da recusa veemente da denominada escola tradicional e do paradigma do instruir. Pode considerar-se, assim, que os discursos analisados se constroem em função quer de um atitude de recusa, quer de uma atitude de afirmação pedagógica, o que significa, então, que tais discursos adquirem visibilidade pública, num primeiro momento, como discursos que se caracterizam por denunciarem (Fernandes, 2003):
a) o estatuto de menorização a que a Esco-
la sujeita os seus alunos;
b) a normatividade metodológica e a unici- dade do método;
c) os programas de estudos estandartizados
e geridos de forma burocrática;
d) as limitações da instrução como modo
de formação. (p. 58-59)

Num segundo momento, os discursos em questão, em articulação com as denúncias atrás referenciadas, tendem a caracterizarse por uma dimensão afirmativa, por meio da qual (Fernandes, 2003):
a) consideram que os alunos deverão cons- tituir o centro de gravidade dos projectos de educação escolar;
b) afirmam os interesses e as necessidades destes alunos como os vectores fundamen- tais da construção e gestão dos programas escolares;
c) valorizam os dispositivos de mediação

2. Recorre-se também a um artigo de Hameline (1994) e um outro de Hameline, Jornod e Belkaid (1995), nos quais há referências à obra e à reflexão de Ferrière.

3. Recorre-se também a um texto de Hameline (1994a) sobre esse pedagogo.

4. Recorre-se a um trabalho de Böhm (1996) sobre a pedagoga italiana. 5. Importa valorizar a obra de uma colaboradora que the é próxima, Amélie Hamaïde (1932), e um trabalho de Dubreucq (1994).

6. Recorre-se a outros textos originais do pedagogo americano contidas na obra de Deledalle (1995). 
pedagógica que são capazes de potenciar as aprendizagens dos alunos, de forma a recusar-se liminarmente as intenções e as acções instrutivas dos professores. (p. 101)

"Estudar, compreender e depois agir; transformar a escola; não permitir que se imponha de fora para dentro, ao corpo e à alma da criança, uma educação que é muitas vezes uma deformação" (Ferrière, 1934, p. XIX). Eis a solução que esse autor encontra para responder à questão que ele próprio nos coloca quando se interroga sobre o "que devemos nós fazer, horrorizados com os processos coercitivos do passado que violentam a natureza humana?" (p. XIX). Uma solução que de algum modo identifica, como se constata, o propósito nuclear de todos aqueles que afirmam a sua pertença ao campo das pedagogias da aprendizagem, a qual deverá ser entendida, então, como uma reivindicação que se referencia não por oposição à escola como instituição educativa, mas às concepções e às práticas derivadas da abordagem tradicional do modelo de educação escolar.

É a recusa de uma escola, subordinada a um tal modelo, que está presente no discurso de Maria Montessori (s.d.) ${ }^{7}$, quando a pedagoga italiana denuncia de forma veemente uma escola onde as crianças se encontravam

\section{[...] fechadas e escravizadas, expostas a um tormento a que a sociedade as obriga. 0 pei- to estreito, que dá predisposição para a tu- berculose, era originado pela permanência aí durante longas horas, curvadas sobre as car- teiras, a ler e a escrever; a coluna vertebral curvava-se devido a essa posição forçada, a miopia era devida ao prolongado esforço do olhar, sem luz suficiente, e, finalmente, todo o corpo se deformava e era quase asfixiado por longas permanências em locais com redu- zido espaço e fechados. (p. 366)}

Uma escola que não só se mostrava incapaz de compreender o sofrimento daquelas muitas crianças que aí entravam "totalmente fatigadas pelo trabalho da manhã" (Montessori, s.d., p. 367), como ainda contribuía para agravar esse mesmo sofrimento quando as obrigava ao confronto com um mestre que "procurava despertar o interesse daquelas crianças exaustas por meio de castigos e impelindo-as à obediência com ameaças” (p. 367). Castigos tão humilhantes como os de "pendurar cartazes infamantes nas costas, colocar orelhas de burro, ou expor o aluno numa verdadeira picota, de forma a que quem passe diante dele se ria e o insulte" (p. 368-369) ou tão dolorosos como os de obrigar as crianças a "permanecer de pé durante horas seguidas, com a cara voltada para um canto da aula” (p. 369). É contra o insustentável projecto de uma escola onde os alunos se comprimem "no meio de instrumentos que degradam o corpo e o espírito: as carteiras, as recompensas e as punições exteriores, de forma a reduzi-los à disciplina da imobilidade e do silêncio" (Montessori, 1958, p. 20) que essa autora se bate, a exemplo de todos os pedagogos que são relacionados com o Movimento da Educação Nova. Um projecto que, para além disso, permite que se conduza os alunos sem outro objectivo que não seja o de se "verter maquinalmente o conteúdo dos programas no seu espírito: programas compilados nos ministérios e impostos por via das leis" (p. 20).

É o percurso que vai da denúncia e da recusa da desumanidade que a escola tradicional dá mostras à necessidade de se reconhecer os alunos como seres tão singulares quanto capazes que justifica, de algum modo, o recurso à obra de Rousseau como reflexão de referência de muitos dos pedagogos do Movimento da Educação Nova. “J. J. Rousseau foi talvez o primeiro que descobriu o valor próprio da juventude", revelando-se, assim, "no seu Émile, o profeta da Escola Activa” (Ferrière, 1934, p. 15), e expressando, por essa via, a importância e a influência dele no que Claparéde (1931), um dia, designará por revolução coperniciana da educação.

7. Essa tradução se fez a partir da primeira versão italiana, editada em 1938. 
Uma influência que se começa a fazer sentir no momento em que Rousseau, para além de definir a criança como um ser distinto do adulto, um ser a respeitar na sua especificidade e virtualidades próprias, define, mais do que isso, a importância da infância no âmbito do processo de sobrevivência da espécie humana e do modo como contribui para que o homem e a mulher adultos se afirmem como tal. A evocação de Rousseau que Cousinet (1978) realiza para comprovar a tese da especificidade da infância face aos adultos é, desse ponto de vista, inequívoca e clara. As crianças, para Rousseau, "têm por assim dizer uma gramática da sua idade, cuja sintaxe é constituída por regras mais gerais do que a nossa e que, se se lhe prestasse a devida atenção, se ficaria espantado com a exactidão com que empregam determinadas analogias, talvez viciosas, mas muito regulares e que apenas são chocantes pela sua rigidez ou porque o uso as não admite" (p. 27-28). É Claparède (1931) quem no-lo recorda quando transcreve as palavras de Rousseau:

Suponhamos que uma criança possuía à nascença a estatura e a força de um homem feito; este homem-menino seria um perfeito imbecil, um autómato, uma estátua imóvel e quase insensível. Não veria bem, não compreenderia nada [...]. Este Homem formado de uma vez só não saberia também erguer-se sobre os seus pés, faltarlhe-ia o tempo bastante para aprender a equilibrar-se [...]. Sentiria a inquietação das necessidades sem as conhecer. (p. 101)

Não se entenda, contudo, que a função da infância se circunscreve a ser uma via de acesso que conduz à idade adulta. A infância, para os rousseaunianos do Movimento da Educação Nova - que não pode ser caracterizado como um movimento rousseauniano, ainda que Rousseau constitua uma figura de referência e a propósito da influência que este exerceu na obra e na reflexão de muitos pedagogos desse movimento -, não é uma adultez imperfeita nem tampouco pode ser definida como um tempo de preparação. Pelo contrário, tem um valor próprio, "um valor positivo" (Cousinet, 1978) e que, por isso,

[...] não se deve manter os olhos da criança postos no fim desse caminho nem guiá-la para que o percorra o mais rapidamente possível, antes pelo contrário deve permitir-se que nele se demore o mais que puder. (p. 29-30)

A afirmação desse novo estatuto da infância, constituindo um dos contributos mais relevantes que se atribui a Rousseau, não é a única expressão da influência que este exerceu sobre a obra dos pedagogos do Movimento da Educação Nova. A Natureza que é uma referência axial sobre a qual se constrói a obra deste assume, igualmente, um papel relevante nos discursos e nas práticas desses pedagogos quer em função do reconhecimento de uma ordem subjacente ao desenvolvimento da criança que a Natureza fixou (Claparède, 1931; Ferrière, 1934; Montessori, [s.d.]; 1958; Cousinet, 1945; 1978), quer em função da valorização da $\mathrm{Na}$ tureza como espaço e recurso educativo, o que constitui uma das imagens de marca do Movimento da Educação Nova, sendo por isso reiteradamente valorizada nos textos de alguns dos seus pedagogos de referência (Montessori, 1958; Cousinet, 1978) e assumida como condição educativa quer no âmbito da definição de Escola Nova que Ferrière propôs - "Internato familiar, situado no campo, onde a experiência da criança serve de base à educação intelectual pelo emprego dos trabalhos manuais e à educação moral, pela prática de um sistema de autonomia relativa dos escolares" (Rocha, 1988, p. 87, grifos meus) -, quer no domínio da fundação de escolas concretas que alguns dos pedagogos relacionados com esse movimento protagonizaram. 0 caso da escola fundada por Decroly em Bruxelas, na Rua de L'Ermitage, é provavelmente um dos casos mais emblemáticos. Criada em 1907, a Escola L'Ermitage é transferida em 1926 para uma zona campestre dos arredores da cidade, de for- 
ma a respeitar-se, por essa via, os "princípios que a fundamentam” (Hamaïde, 1932, p. 26).

Essa concepção de uma ordem natural prévia, a partir da qual se deve definir a educação da criança e que justifica, por exemplo, que Ferrière (1934) afirme que "a criança cresce como uma plântula em conformidade com leis que the são próprias" (p. 5), é uma concepção que, no âmbito do Movimento da Educação Nova, tanto é partilhada, se bem que de forma distinta nos textos de alguns dos seus pedagogos, como é igualmente relativizada nos textos produzidos por outros. Dewey (1966), que se insere nessa última categoria, assume uma posição bastante relevante. Clarificando a posição de Rousseau, para quem, segundo a sua opinião, "é suposto que a Natureza forneça a lei e as finalidades do desenvolvimento, daí que seja necessário seguir e conformar-se com os seus caminhos" (p. 112), considera que, por um lado, esta é uma abordagem com pontos positivos, já que denuncia o erro daqueles que definem as finalidades educativas sem ter em consideração o potencial de desenvolvimento humano das crianças. Por outro lado, mostrase uma concepção algo vulnerável quando o natural, como categoria normativa, não só se confunde com o físico, como permite também que se defenda que nada temos a ver com o processo de desenvolvimento das crianças, já que aquilo que é necessário é que a Natureza possa realizar o seu trabalho. Daí que Dewey afirme ser necessário que "os escritos de Rousseau sejam cuidadosamente estudados", que "sejam lidos nas suas entrelinhas" (p. 113) e que sejam também confrontados com outras intervenções protagonizadas pelo próprio Rousseau.

Embora se compreenda, no âmbito do pensamento de Rousseau, que a valorização da existência de uma ordem natural prévia é um argumento decorrente da afirmação do Homem como um ser natural, cuja degenerescência como ser social provém, nessa perspectiva, da ruptura que se foi estabelecendo, à medida que a civilização humana evoluía, entre o ser humano e a Natureza (Soetärd, 1994), há que reconhecer que, pelo menos do ponto de vista das suas implicações educativas, tal afirmação não poderá ser nem desvalorizada nem iludida quando se aborda quer as obras daqueles que se situam no campo das pedagogias da aprendizagem, quer, em particular, as obras daqueles que se situam no âmbito do Movimento da Educação Nova. A valorização de uma ordem natural prévia ao desenvolvimento da criança, entendida como o garante desse mesmo desenvolvimento, comprova que esta nunca foi uma questão pacífica no seio desse. Se se afirma a posição de Dewey quanto à problemática em apreço, importa referenciar, também, a perspectiva de Maria Montessori e a leitura que esta faz da obra de Rousseau, por via da influência exercida por Itard na sua própria obra, poderemos, então, concluir que nos encontramos perante uma problemática que não é recente. Referindo-se a Itard, Montessori (1958) escrevia:

[...] ele acreditava na omnipotência da educação, contrariamente ao princípio de J. J. Rousseau que anunciou, antes da Revolução: "Tudo está bem quando sai das mãos do Autor das coisas, tudo degenera nas mãos do Homem". (p. 52)

Nesse momento, contudo, importa apenas referir a sua centralidade no seio da reflexão produzida pelos pedagogos desse movimento por força da influência da obra de Rousseau, quer para acusar a educação tradicional de desrespeitar e agredir a natureza da criança ${ }^{8}$, quer para afirmar alguns dos princípios estruturantes do seu projecto educacional e legitimar muitas das soluções pedagógicas que propuseram, embora se deva reconhecer, como o faz Michel Soetärd (1994) que a leitura de Rousseau por parte dos pedagogos do Movimento da Educação Nova nem sempre se encontra isenta de mal-entendi-

8. Talvez seja esse o momento de reconhecer, neste trabalho, que a valorização da existência de uma ordem natural prévia ao desenvolvimento da criança pode ser entendida, apesar dos seus eventuais equívocos, como a expressão de um discurso reactivo contra os desmandos pedagógicos e humanos das práticas que tinham lugar nas escolas e às quais os pedagogos do Movimento da Educação Nova se opuseram, em alguns casos, de forma bastante voluntarista e inflamada. 
dos que têm a ver, "indubitavelmente, com o pretenso naturalismo de Rousseau” (p. 35).

Haja, ou não haja, uma leitura imediatista de Rousseau por parte de alguns daqueles pedagogos, o que é certo é que quer a afirmação da infância como um período específico da vida dos seres humanos, quer a afirmação da existência de uma ordem natural que importa respeitar ou reconhecer em cada criança, se converteram, ambas, em duas afirmações nucleares no âmbito do Movimento da Educação Nova, cuja importância tem a ver, entre outras coisas, pelo modo como contribuíram para a emergência do conceito de "educação negativa” (Claparède, 1931; Soetärd, 1994). Conceito esse que, para além de constituir mais um contributo no âmbito do processo de denúncia da escola tradicional, se configurou também como um dos desafios pedagógicos mais ambiciosos que se colocaram aos pedagogos do Movimento da Educação Nova e, em geral, a todos os que integram o campo das pedagogias da aprendizagem.

A afirmação de um projecto que se define como de educação negativa é o corolário da afirmação da centralidade da criança no âmbito de qualquer processo de carácter educativo e constitui a resposta ao desafio que Soetärd (1994) faz quando se questiona sobre o jogo de forças que se estabelece entre o adulto e a criança.

Será que eu vou transformar, a qualquer momento, o meu poder sobre a criança numa atitude, num acto, que por uma interposta instituição, vai fazer do outro instrumento da minha vontade ou irei usar esse mesmo poder no sentido de promover a sua liberdade? (p. 30)

Numa perspectiva rousseauniana, a resposta a essa questão, segundo Soetärd, passa por reconhecer que toda a arte do pedagogo consistirá em "manifestar a sua força respeitando a vontade da criança, quer dizer, evitando ditar-lhe tudo o que ela deverá fazer" (p. 30). É esse, então, o sentido de uma "educação negativa", o qual encontra legitimidade, como afirma Claparède (1931), na necessidade de respeitar a "ordem da Natureza” (p. 107), tal como Rousseau o defende quando escreve:

Deixai agir a Natureza antes de vos atreverdes a agir em seu lugar, de tentar contrariar as suas operações [...]. A natureza possui, para fortificar o corpo e o fazer crescer, meios que não deveremos contrariar. (p. 107)

Daí que Claparède conclua que "nada é mais prejudicial do que intervenções intempestivas; mais vale nada fazer do que fazer mal; assim, na dúvida, abstém-te" (p. 107). Mais vale nada fazer. Um nada fazer que merece ser esclarecido, sobretudo, quando parece ser esta a divisa que melhor consubstancia o conceito de "educação negativa".

"Jovem professor, imploro-te uma arte difícil, a de governar sem preceitos e a de tudo fazer não fazendo nada" (Rousseau apud Soetärd, 1994, p. 30). Pode concluir-se daqui que uma "educação negativa" implica obrigatoriamente a negação do papel, como educadores, dos professores e dos adultos, em geral? A haver negação, negam-se, sobretudo, as intervenções educativas excessivas que se afirmam de fora para dentro; as intervenções que impedem ou perturbam o desenvolvimento da criança. Daí que mais do que concluir que a “educação negativa” nega, penso que seria mais adequado constatar que ela afirma. Afirma, de forma talvez demasiado optimista, como a criança é potencialmente capaz de cumprir os desígnios da Natureza - na versão rousseauniana - ou da Vida - na versão montessoriana (Montessori, 1958), desde que não a impeçam de o fazer. É esse não impedir, é essa recusa do professor e do adulto como um obstáculo educativo que o conceito de "educação negativa" pretende e permite valorizar. Desse modo, conclui-se que, de acordo com esse conceito, educar não consiste tanto em recusar intervir, mas mais em recusar intervir de forma abusiva. 1sto é, de intervir substituindo os alunos nas tarefas que só a eles dizem respeito, fazendo por eles o que só 
a eles compete fazer, impondo-lhes um ritmo de aprendizagem que lhes é estranho, desvalorizando os seus interesses e as suas necessidades ou subestimando a importância de estimular e valorizar as suas experiências pessoais aos mais diversos níveis.

Será John Dewey que ampliará o campo argumentativo em função do qual se defende a necessidade de se transitar do paradigma da instrução para o paradigma da aprendizagem. Fêlo a partir de outros referenciais que importa valorizar, porque, de algum modo, são percursores de uma leitura na qual parece que já se assume, ainda que de forma algo implícita, alguns dos paradoxos que sustentam o campo das pedagogias da aprendizagem. É que a transformação educativa das escolas, para Dewey (2002), tem mais a ver com a necessidade de relacionar tal transformação com as "mudanças na situação social e o esforço para satisfazer as necessidades da nova sociedade que está a formar-se, à imagem do que sucede com as alterações que assistimos nos campos da indústria e do comércio" (p. 18), do que propriamente com a necessidade de se exaltar o reconhecimento da natureza singular das crianças como factor potenciador de tal transformação.

Para esse autor, tais necessidades são uma consequência da revolução industrial, "uma revolução tão rápida, tão extensa e tão completa" (p. 19) que é inconcebível pensar que esta "não afectará a educação senão dum modo formal e superficial" (p. 20). "0 que ocorreu foi uma mudança radical das condições de vida, e só uma mudança igualmente radical no campo da educação produzirá resultados palpáveis” (p. 22). Nesse sentido, e tendo em conta que aquilo que "impede a escola dos nossos dias de se organizar como uma unidade social natural é exactamente a ausência desta componente de actividade comum e produtiva" (p. 24), importa, então, compreender a necessidade da mudança e da extensão desta, já que nas salas de aula, das escolas subordinadas a uma racionalidade pedagógica tradicional, "faltam o motivo e o cimento da organização social" (p. 24), o que leva Dewey a concluir:
[...] ponto de vista ético, a trágica debilidade da escola de hoje reside na sua ambição de preparar os futuros membros do tecido social num meio em que as condições do espírito social faltam visivelmente. (p. 24)

Acusação que especifica, posteriormente, quando afirma que "o trabalho escolar consiste apenas em decorar as lições" e "a assistência mútua, em vez de ser a forma mais natural de cooperação e associação, torna-se num esforço clandestino para aliviar o parceiro dos deveres que lhe incumbem" (p. 25), de tal forma que "o facto de uma criança ajudar outra nas suas tarefas passou a ser considerado um delito" (p. 25). Daí que a mudança seja não só necessária como imprescindível. Uma mudança que, entre outras coisas, terá que afectar

\section{[...] os nossos métodos escolares e, em grande medida, os nossos programas de estudos [...], heranças do período em que era de importância fulcral a aprendizagem e o domínio de certos símbolos, que faculta- vam a única via de acesso ao saber. (p. 33)}

Uma mudança que afecte, também, o círculo vicioso descrito por Dewey, quando demonstra como a

[...] uniformidade mecânica dos programas e dos métodos cria uma espécie de imobilidade uniforme que contribui, por sua vez, para perpetuar essa uniformidade dos programas e das recitações. (p. 62)

Condição da falta de sentido da actividade dos alunos na escola e do mal-estar crescente que o clima repressivo, gerado por essa uniformidade forçada, explica, na medida em que ao contribuir para ignorar ou para contrariar os interesses dos alunos, acaba por estimular a sua afirmação por meio de caminhos mais ou menos proibidos (Dewey, 1963). Eis-nos perante uma reflexão de natureza distinta das anteriores, não tanto quanto às implicações pedagógicas destas, mas mais 
quanto aos seus fundamentos epistemológicos e conceptuais. Uma reflexão que não partilha, pelo menos, de alguns dos paradoxos nucleares que marcam as leituras de muitos dos pedagogos que se relacionam com o Movimento da Educação Nova, as quais determinam, afinal, os equívocos do próprio campo das pedagogias da aprendizagem.

Para Dewey (2002), a transformação pedagógica que este preconiza tem mais a ver com a necessidade de as escolas reconhecerem e valorizarem "a força em desenvolvimento inerente à experiência presente da criança” (p. 167) do que obrigar as escolas "a adaptar a marcha do seu ensino à marcha natural da evolução psicológica” (Claparède, 1972, p. 200). Isto é, na reflexão que Dewey nos propõe, a possibilidade de se gerarem actividades significativas no âmbito das escolas passa, então, por reconhecer o sentido social e cultural de tais actividades, as quais obrigam os alunos a confrontar e a interpelar a sua experiência no presente, tendo como referência as experiências da humanidade de que são parte integrante. Pese os equívocos da reflexão de Dewey - nomeadamente a "lógica do alargamento progressivo" (Roldão, 1994, p. 73) que é um dos traços marcantes da sua abordagem pedagógica ou o empirismo epistemológico que, por vezes, dá mostra, particularmente quando define "o "saber como fazer' como o primeiro passo necessário no processo de aquisição de conhecimentos" (p. 73) -, importa reconhecer que tal reflexão permite enfrentar alguns dos paradoxos que afectam o campo das pedagogias da aprendizagem, no qual se evidencia, como paradoxo nuclear, aquele a partir da qual se defende que o processo de humanização, construído em qualquer circunstância por meio de artifícios culturais cuja finalidade consiste em promover a desnaturalização do ser humano, deve respeitar uma Natureza contra a qual, e em certa medida, esse processo se constrói. Paradoxo esse que sustenta um outro que permite evidenciar que, por sua vez e na perspectiva em causa, o reconhecimento das singularidades humanas, entendido como condição de uma educação mais adequada à humanidade das crianças, deriva da necessidade de se reconhecer a ordem inquestionável, invariante e universal que a Natureza legitimaria. Um propósito que nos permite considerar que, mais do que o reconhecimento das singularidades dos indivíduos, o que parece interessar os subscritores de tal perspectiva são, afinal, as invariâncias humanas.

É a partir, assim, dos dois paradoxos acabados de enunciar que podemos identificar um terceiro, já implícito nos anteriores, por meio do qual se visa encontrar na natureza da criança a fonte de legitimação de uma acção educativa mais humana, a qual, por isso mesmo, tende a ser definida como uma acção educativa que não é susceptível de ser questionada.

A natureza da criança constitui-se, desse modo, como um recurso argumentativo, suficientemente central e potente que, mais do que o resultado da observação de crianças que agem livremente e sem constrangimentos, é acima de tudo a expressão de opções teóricas prévias que, veja-se o caso da reflexão proposta por Maria Montessori, traduzem o compromisso entre o biologismo dos seus "instintos-guia" 9 ou dos seus "períodos sensíveis" (Montessori, s.d., p. 74) e a cosmogonia religiosa que a leva a afirmar que "logo que se descubra as leis do desenvolvimento da criança, descobrir-se-á o espírito e a sabedoria de Deus que age na criança" (Montessori apud Böhm, 1996, p. 156).

0 recurso aos "instintos-guia” para se referir à dimensão cósmica da vida, ilustra inequivocamente esse pressuposto.

A estes 'instintos-guia' está ligada a própria existência da vida, na sua elevada função cósmica e, embora sejam reacções em face do meio, constituem delicadas sensibilidades internas, 'dentro da vida', tal como o pensamento puro é uma característica to-

9. "Neste campo, a biologia conseguiu mostrar o aspecto criador e conservador da espécie, descobrindo os instintos que guiam interiormente os seres vivos e que, para os distinguir do conjunto de instintos impulsivos referentes às reacções imediatas do ser, em face do meio, se podem chamar 'instintos-guia'." (Montessori, s.d., p. 347) 
talmente interior da mente. Prosseguindo a comparação, poder-se-iam considerar os pensamentos divinos que se elaboram no intimo dos seres vivos que depois impelem estes a actuar em acções no meio exterior. (Montessori, s.d.; p. 348)

Montessori (s.d.) recorre à noção de períodos sensiveis, inspirando-se na obra do biólogo Hugo de Vries, para caracterizar, de algum modo, o seu investimento. Daí que afirme:

Foi o sábio holandês Hugo De Vries quem descobriu os períodos sensíveis nos animais, mas fomos nós nas nossas escolas, na vida das crianças e na família que ca-racterizámos estes períodos sensiveis no crescimento infantil e os utilizamos na educação. (p. 74)

É que para a pedagoga italiana os "períodos sensíveis são muito poderosos: são a força excitante da Natureza criadora” (p. 109), sendo necessário tê-los em consideração como factor educativo, já que são eles que permitem compreender que tudo se deve fazer "tranquila e inadvertidamente, até que as condições do ambiente exterior correspondam às suas [da criança] necessidades internas” (p. 83). É que, constata ela, do mesmo modo que "o adulto, do exterior, não tem qualquer influência” (p. 77) sobre esses diversos períodos, também a criança, caso não possa "actuar segundo as directrizes do seu período sensível” (p. 77), corre o risco de perder "a oportunidade de uma conquista natural” (p. 77) e, se isso acontece, corre mesmo o risco de a perder para sempre.

Dessa forma, um pressuposto que se constitui como um dos equívocos centrais de uma parte considerável do património de reflexões que os pedagogos do Movimento da Educação Nova foram construindo, o qual se revela mediante a tentativa de identificar como obra da Natureza, é uma obra, por via disso, indiscutível, que não é mais do que uma obra humana, necessariamente contingente, produto do tempo e do espaço em que a gerámos.
A rede de paradoxos completa-se, por fim, quando nos confrontamos com a obra de Decroly, a qual assenta numa afirmação nuclear - a de que é "da criança que tudo irradia" (Decroly apud Dubreucq, 1994, p. 267) - que sustenta e legitima, por exemplo, o dispositivo dos "centros de interesse" (Hamaïde, 1932; Decroly; Hamaïde, 1932; Decroly, 1965) em função do qual Decroly assume a pretensão de organizar os programas de estudo e de trabalho nas escolas, respeitando os interesses e as necessidades dos alunos, como se estes fossem seres autossuficientes, tal como se infere da afirmação de Cousinet (1945) quando afirma que "as crianças sabem perguntar com precisão, tiverem mesmo necessidade disso, informações ou conselhos" (p. 58), até porque, para o referido pedagogo, só se "deve ensinar as crianças se, ao fazê-lo, se responder a uma necessidade da sua natureza. Ensina-se porque elas desejam ser ensinadas" (p. 13).

É a partir desse tipo de posicionamento que se explica o mal-estar que se faz sentir no campo das pedagogias da aprendizagem quando aí se debate a influência educativa como uma problemática de carácter pedagógico. É que, como afirma Claparède (1972), se é necessário "fazer corresponder os interesses de cada grau de ensino aos interesses naturais que caracterizam os diversos estádios da evolução infantil” (p. 232), então, mais do que exercer uma influência, aqueles que educam devem permitir que os alunos possam autorregular as suas aprendizagens e os percursos que conduzem a elas. Nesse sentido, no campo das pedagogias da aprendizagem, a problemática da relação educativa tende a obscurecer a da influência educativa, quando eclipsa o papel do património cultural como um dos polos das acções educativas a promover. 0 paradoxo, nesse caso, tem a ver, então e em primeiro lugar, com o facto de se promover uma concepção em que a aprendizagem dos alunos tende a ser identificada como uma operação que, pelo menos do ponto de vista dos discursos de uma parte significativa dos pedagogos 
do Movimento da Educação Nova, por meio dos quais se enunciam os fundamentos e os princípios das suas propostas educacionais, se circunscreve essa aprendizagem a uma espécie de momento de autorrevelação, em função do qual os alunos se consciencializariam dos seus interesses, das suas necessidades e, consequentemente, das suas possibilidades de reflectir e de agir. 0 paradoxo, assim e em segundo lugar, tem a ver, por isso, com o modo como tal abordagem desvaloriza a qualidade do contacto com o património cultural de que hoje dispomos, sobretudo quando esse contacto se transforma num confronto, e este, porque podendo conflituar com aqueles interesses e necessidades, tenderia, por um lado, a impedir aquelas aprendizagens e, por outro, a ser ignorado igualmente como uma condição necessária à sua ocorrência.

Até que ponto é que esses paradoxos se mantêm como alguns dos eixos pedagógicos estruturantes do campo das pedagogias da aprendizagem? Quais as respostas que, eventualmente, se foram construindo para enfrentar tais paradoxos?

São essas duas questões, entre outras passiveis de ser evocadas, que justificam o propósito, já anunciado neste artigo, de analisar as propostas de reflexão e de acção pedagógica do MEM, de forma a compreender-se até que ponto, e como, é que nesse movimento, por um lado, se foram confirmando, ignorando ou rejeitando os pressupostos e as respostas que alicerçam os campos das pedagogias da aprendizagem e, por outro, quais as alternativas que, quer do ponto de vista conceptual, quer do ponto de vista da acção pedagógica e didáctica, se foram construindo no seio de tal movimento.

\section{- MEM e o seu contributo para a interpelação do campo das pedagogias da aprendizagem}

Foi a partir da leitura e análise de textos produzidos no âmbito do MEM - (i) 200 artigos incluídos em todos boletins e revistas "Escola Moderna", propriedade do movimento e publicados desde o seu primeiro número até 2003; (ii) 2 monografias; (iii) 7 textos de apoio; (iv) 4 Cadernos de Formação Cooperada; (v) 7 textos incluídos num quinto Caderno de Formação Cooperada; e (vi) 24 obras que foram objecto de publicações no exterior do MEM que um tal empreendimento foi realizado, permitindo concluir que o contributo daqueles que intervêm a partir daquele movimento se fez sentir, em larga medida, em função:

a) da afirmação de uma racionalidade pedagógica de tipo sociocêntrico dos projectos de educação escolar que contrasta com a abordagem puerocêntrica dos pedagogos do Movimento da Educação Nova;

b) da afirmação da escola como um espaço de interlocução cultural;

c) da valorização das aprendizagens dos alunos como condição da afirmação, não do campo das pedagogias da aprendizagem, mas do campo das pedagogias da comunicação.

A abordagem de uma racionalidade sociocêntrica dos projectos de educação escolar que constitui, hoje, uma das imagens de marca do MEM ocorre, de forma implícita, em função da importância que as técnicas Freinet assumiram na configuração inicial das práticas pedagógicas dos professores relacionados com aquele movimento (Fernandes, 2003) e, posteriormente, afirma-se de forma explícita quer sob a influência da reflexão de Fernand Oury (1977; 1977a; 1977b; 1977c; 1978; 1988) e da corrente da pedagogia institucional que este foi animando, quer do peso que, sobretudo, as obras de Vygotsky $(1978 ; 1987 ; 1998)$ e Bruner (1990; 2000; 2002) assumem, hoje, como referências teóricas e metateóricas do tipo de abordagens educativas que, actualmente, caracterizam as leituras e as acções pedagógicas que se desenvolvem sob a égide do MEM. A influência desses dois autores sobre o ideário e a configuração do modelo pedagógico do MEM faz-se por via directa, mas também por meio de outros investigadores que encontram neles as referênci- 
as nucleares da reflexão educativa que produzem, os quais, no seu conjunto, contribuem para configurar o que podemos designar por abordagem socioconstrutivista no campo da Educação. Nesse caso, não nos podemos esquecer, por isso, do contributo de investigadores como, entre outros, Harry Daniels (2003), Clotilde Pontecorvo (2005) ou Barbara Rogoff (2005).

É a assunção de uma racionalidade pedagógica de tipo sociocêntrico que permite que no seio do movimento em causa se afirme que não são os alunos, individualmente considerados, que deverão constituir o eixo pedagógico nuclear dos projectos de formação que têm lugar nas escolas, mas a organização social do trabalho de aprendizagem, a qual, por isso, deverá contribuir para a construção de comunidades de aprendizagem onde cada um aprende à medida que os outros aprendem e se sabe que todas as aprendizagens são pessoais, ainda que ninguém aprenda sozinho. São essas comunidades de aprendizagem que suportam, justificam e potenciam o processo de formação singular de cada um dos membros dessa comunidade à medida que estes participam, aprendendo, assim, a participar quer na gestão cooperada dos planos curriculares de turma, das actividades ou do espaço e do tempo de trabalho nas salas de aula, quer nos momentos, nos procedimentos e nas estratégias de hetero e autorregulação tanto dos compromissos de carácter académico e comportamental que se estabelecem no âmbito desses contextos educativos, como das actividades e dos acontecimentos que aí ocorrem.

É num texto da autoria de Sérgio Niza (1998), um dos fundadores do movimento, justamente intitulado A organização social do trabalho de aprendizagem no $1^{\circ}$ Ciclo do Ensino Básico, que se revela de forma inequívoca a importância estratégica que a abordagem sociocêntrica assume, hoje, para o MEM, balizando a reflexão que, sob a sua égide, se constrói quer sobre a organização do trabalho pedagógico, quer sobre os processos e as estratégias de mediação curricular e didáctica, quer, em geral, sobre os sentidos dos projectos de educação escolar. É nesse texto que, no subcapítulo Construindo a formação democrática, Niza identifica os três eixos estruturantes do modelo pedagógico do MEM, por meio dos quais se consubstancia a já referida racionalidade sociocêntrica, a saber: (i) "os circuitos de comunicação" (p. 78); (ii) "as estruturas de cooperação educativa” (p. 79); e (iii) "a participação democrática directa” (p. 82), os quais sustentam tanto o modo como se organiza temporalmente o trabaIho na sala de aula e o próprio espaço que esta constitui, como o "sistema de pilotagem do trabalho de cooperação educativa” (p. 91), onde se enquadram: (i) os instrumentos de planeamento, dos quais os planos semanais, os diários ou, entre outros, os individuais de trabalho são referências exemplares destes; (ii) os instrumentos de pilotagem, dos quais se referem os projectos curriculares de turma, os mapas de tarefas ou os registos das actividades realizadas; e (iii) os instrumentos de avaliação que se utilizam (Niza, 1998), os quais, no seu conjunto, sustentam

[...] uma observação formativa que guia (pilota), controla e regula, com a participação directa dos alunos e do professor, de forma sustentada, o desenvolvimento do trabalho de aprendizagem suscitado pelos programas curriculares, pelos alunos, pelo professor ou por outros colaboradores da turma. (p. 94)

Pode considerar-se que a racionalidade sociocêntrica que assume um posicionamento estratégico nuclear no âmbito da configuração do modelo pedagógico do MEM não poderá ser dissociada da afirmação da escola como um espaço de interlocução cultural. É que essa racionalidade, sustentáculo do Movimento da Educação Nova, ao alimentar a crença de que a educação das crianças não deveria contrariar a ordem natural que determinava a ordem do seu desenvolvimento, prescrevendo-se, por essa via, a nova ordem educativa a respeitar, tendia a estabelecer uma tensão improdutiva e 
equívoca entre Natureza e Cultura, definindo-se, ainda que de forma nem sempre explícita, uma relação que tenderia a privilegiar a relação Natureza-Educação em detrimento da relação Cultura-Educação.

Com a afirmação de uma racionalidade pedagógica de tipo sociocêntrico, é esse último eixo que se passa a privilegiar, sem que isso possa significar que os alunos passem a ocupar uma situação subalterna como actores educativos ou que, por isso, estes possam ser desvalorizados como seres detentores de saberes e de inteligência. Eles são entendidos como um dos polos incontornáveis de um processo mais amplo de diálogo, em função do qual se transita de uma relação naturalizada com o saber para a construção de uma relação de interlocução com esse mesmo saber. Assim, a relação que os alunos estabelecem com o património cultural deixa de ser legitimada em função de argumentos por meio dos quais se enaltece o respeito pela sua natureza específica como condição do estabelecimento de uma relação harmoniosa entre ambos. Mais do que respeitar o desenvolvimento psicológico como o eixo em função do qual se legitima o sentido das acções de natureza educativa que têm lugar nas escolas, o que se defende, agora, é a necessidade de os processos de educação escolar respeitarem "os processos sociais autênticos da construção da cultura nas ciências, na arte e no quotidiano" (Niza, 1996, p. 143). Nesse sentido, o desenvolvimento psicológico é uma variável a considerar, entre outras possíveis, no momento em que nos permite compreender melhor os contornos específicos de uma relação que é marcada pelas singularidades dos alunos e as particularidades epistemológicas e conceptuais dos saberes com os quais estes se têm que relacionar, quer como condição que justifica qualquer acto educativo, quer como condição do seu desenvolvimento e afirmação como pessoa.

Em suma, comparando as propostas do Movimento da Educação Nova com as propostas do MEM, pode afirmar-se que, de um tal confronto, se anuncia uma transição fundamen- tal do campo das pedagogias da aprendizagem para o campo das pedagogias da comunicação (Fernandes, 2003). Uma transição que não visa pôr em causa o facto do acto de aprender continuar, nesse âmbito, a constituir uma finalidade nuclear da acção educativa que tem lugar nas escolas, mas tão somente a enquadrálo num espaço conceptual cuja arquitectura quanto aos seus fundamentos e pressupostos pedagógicos é distinta. Um espaço conceptual que obriga a repensar o papel dos alunos, o dos professores e, igualmente, o do património de saberes já constituído que, nesse processo de reorientação pedagógica, ocupa um lugar decisivo no modo como influencia e baliza quer a reflexão sobre os outros polos da relação educativa, quer a própria reflexão sobre as implicações educativas de um tal processo.

Ainda que uma análise mais ponderada nos aconselhe a uma leitura prudente das obras e dos contributos dos pedagogos do Movimento da Educação Nova, de forma a evitarem-se conclusões precipitadas, não tanto sobre os fundamentos e os pressupostos do ideário pedagógico daquele movimento, mas sobre as suas reflexões e propostas didácticas, importa reconhecer que, no seio do MEM, podem-se identificar alguns contributos decisivos para enfrentar os equívocos, os paradoxos e as zonas de ambiguidade que foram sendo identificadas como propriedades dos discursos quer do Movimento da Educação Nova, quer do próprio campo das pedagogias da aprendizagem. Esse confronto - entre a natureza da reflexão que a generalidade dos pedagogos do Movimento da Educação Nova produz sobre os fundamentos e os pressupostos que sustentam o ideário pedagógico e a natureza da reflexão e das propostas didácticas que esses mesmos pedagogos produzem - é um factor que não poderá ser desvalorizado quando se analisa o contributo pedagógico desse movimento. É que nem sempre a reflexão sobre os pressupostos e os fundamentos pedagógicos que esses pedagogos defendem coincide com os sentidos das propostas de intervenção que por si são propostas. Ainda que sejam de- 
fensores de uma racionalidade pedagógica de tipo puerocêntrico, em função da qual tendem a iludir ou a ignorar, como objecto de reflexão teórica, a importância e o peso da influência educativa exercida pelos professores não deixam posteriormente, no domínio do espaço dedicado à operacionalização de um tal ideário, de propor dispositivos de acção pedagógica que são, em si, manifestações de influência educativa, tal como é o caso, por exemplo, da organização minuciosa do trabalho que Montessori (1958) defende para as suas Casas dei Bambini; das propostas de Cousinet (1945) face ao trabalho livre de grupo; da própria metodologia de projecto que nos foi legada por Kilpatrick (2006); do sistema Winnetka de ficheiros autocorrectivos de Washburne (1934) ou do Plano Dalton que Parkhurst (1922) desenvolveu para promover a individualização do ensino. Isso significa que os pedagogos do Movimento da Educação Nova e, em geral, aqueles que se situam no campo das pedagogias da aprendizagem não foram capazes, por razões várias, de conferir visibilidade teórica a muitas das iniciativas que propuseram e concretizaram, o que, constituindo uma das vulnerabilidades do seu legado, não justifica, contudo, algumas das leituras simplistas que tendem a desvalorizar o património pedagógico que foram construindo por via quer da generosidade e da perseverança que deram mostras, em termos dos fundamentos e dos pressupostos que sustentam os seus ideários pedagógicos, quer também do ponto de vista da sua intuição e, sobretudo, da centralidade que atribuíram à reflexão pedagógica como condição do exercício da função docente.

Assim, se para aqueles que se situam nesse campo o acto de educar tende a ser entendido como um contributo para o desenvolvimento integral dos alunos, o que passa, em larga medida, por favorecer o seu processo de autoeducação, para o MEM e para o que já designei, neste artigo, por campo da pedagogia da comunicação, educar é permitir que alguém se afirme como pessoa, mediante as experiências pessoais e soci- ais que a partilha e a apropriação de um dado património cultural suscita. Nesse sentido, privilegia-se o acto educativo como um acto de intereducação, sem que se ponha em causa, contudo, a dimensão autoeducativa desse mesmo acto. 0 que acaba por distinguir os dois campos tem mais a ver com o facto de se reconhecer, no campo das pedagogias da comunicação, que os momentos de autoeducação, entendidos como o corolário daquele acto, são possíveis como momentos que derivam e dependem do facto de se entender o acto de educar como um acto de diálogo, de interpelação e até de confronto com os outros, directamente ou por meio do património que nos foi legado. Sendo, no mínimo, pouco rigoroso afirmar que, no campo das pedagogias da aprendizagem, se desvaloriza a interacção com os outros e com o património cultural disponível, vale a pena reconhecer que o que distingue a reflexão nesse campo daquela que se produz no campo das pedagogias da comunicação não é tanto essa desvalorização, mas o estatuto pedagógico que em cada um dos campos referidos assume essa interacção e, sobretudo, o modo como tal interacção é objecto de explicitação teórica no segundo dos campos enunciados.

É a partir dessa constatação que nos podemos confrontar com o peso que os interesses e as necessidades dos alunos assumem nas reflexões pedagógicas que se produzem nos dois campos que tenho vindo a invocar. Para aqueles que se situam no campo das pedagogias da aprendizagem, o acto educativo deve partir das concepções, dos interesses e das necessidades dos alunos como factores capazes de suscitar aprendizagens significativas, enquanto que, no campo das pedagogias da comunicação, a valorização das concepções dos interesses e das necessidades dos alunos é condição necessária, mas não é condição suficiente para promover e alimentar tais aprendizagens.

É perante esses dois cenários pedagógicos que o papel dos professores tende a ser abordado de forma distinta. No caso do campo das pedagogias da aprendizagem, os docentes são entendidos, do ponto de vista das 
formulações que tendem a captar a sua actividade, como organizadores de ambientes de aprendizagem, uma função que não é recusada por aqueles que se situam no campo das pedagogias da comunicação, ainda que não seja entendida como função subordinante, mas subordinada. Para estes, os professores são organizadores de ambientes de aprendizagem porque deverão ser entendidos, acima de tudo, como interlocutores qualificados (Cosme, 2006), contribuindo, assim, quer para promover uma tal organização, quer para que os seus alunos se apropriem e participem tanto na configuração dessa organização, como assumam, a seu modo e também, o papel de interlocutores. Enquanto que para os primeiros o papel do professor se restringe, pelo menos em termos discursivos, ao de um animador de aprendizagens, desafiando, criando ambientes de trabalho, incentivando e promovendo a partilha, para os segundos, tal papel não só deixa de ficar circunscrito ao acto de ensinar, como, sobretudo, se configura de forma mais complexa e ampliada, ensinando quando for caso disso, organizando, desafiando, propondo, apoiando a encontrar e a gerir recursos culturais ou estimulando a reflexão dos alunos. Trata-se, se quisermos, de uma consequência derivada da assunção de uma consciência estratégica da relação tendencialmente tensa que se estabelece entre o conhecimento pessoal dos alunos e o que é tido por conhecido por meio da cultura, o que contrasta com a consciência ingénua e voluntarista que, no campo das pedagogias da aprendizagem, tende a configurar a relação entre os alunos e o património cultural de que podemos dispor como uma relação mais ou menos harmoniosa e distendida.

De algum modo, encontra-se na dimensão da reflexão pedagógica acabada de enunciar um dos aspectos mais marcantes das divergências que se podem estabelecer entre os dois campos em confronto. É que enquanto para o campo da pedagogia da comunicação as aprendizagens dos alunos não poderão ser asseguradas pela actividade docente dos professores, os quais só se poderão comprometer a partici- par activamente na gestão do processo de comunicação que poderá criar as condições para que tais aprendizagens ocorram, para aqueles que se situam no outro campo pedagógico a que nos temos vindo a referir, as aprendizagens só são possíveis se os professores não impedirem os alunos de as realizar, correndo-se até o risco de circunscrever o olhar sobre os professores aos momentos em que a sua acção tende a ser vista, sobretudo, como um obstáculo à aprendizagem dos seus alunos.

Retoma-se, assim e por essa via, o debate sobre a problemática da influência educativa como problemática pedagógica primeira, já que é em torno desta que se pode compreender melhor a necessidade de se transitar do campo da pedagogia da aprendizagem para o campo da pedagogia da comunicação, como resposta alternativa às limitações, aos equívocos e às contradições do paradigma do instruir.

\section{A problemática da influência educativa: uma problemática a interpelar}

Face ao exposto, pode concluir-se que é, em larga medida, pelo modo como os campos pedagógicos da aprendizagem e da comunicação enfrentam a problemática da influência educativa que se pode estabelecer o eixo de fractura que os separa. É que enquanto para o primeiro tal problemática não é objecto de uma preocupação teórica explícita, sendo até expressão de alguns dos equívocos mais marcantes desse campo pedagógico, para o segundo, essa é uma questão em aberto que, de algum modo, constitui um indicador do imenso e intenso trabalho de reflexão que há para fazer para se configurar a acção educativa como um processo de comunicação, sobretudo quando se sabe que tal processo, no âmbito da educação escolar, não acontece por acaso nem segundo a vontade estrita daqueles que nele se encontram envolvidos. Uma ilusão que a racionalidade pedocêntrica acalentou no momento em que contornou, em termos de reflexão teórica, a problemática do confronto com o patri- 
mónio cultural e das possibilidades de os alunos se apropriarem e recriarem esse património como se estivéssemos perante um acontecimento inevitável.

Chegou, pois, o momento de afirmar que a aprendizagem de quem quer que seja deriva, sobretudo, de uma possibilidade que se oferece, mais do que um propósito que se determina. Uma possibilidade que pode ser concretizada em função da oportunidade que um acto educativo, organizado tão intencionalmente quanto possível como um acto de comunicação, pode suscitar e animar. Embora se ponha em causa, nesse paradigma pedagógico, a omnipotência do professor como uma entidade que determina o saber do aluno, não se põe em causa a possibilidade de o primeiro se assumir como um personagem incontornável no âmbito do processo de aprendizagem do segundo, desde que se compreenda os limites e até o paradoxo de uma intervenção que obriga esse primeiro a fazer algo por esse segundo, sabendo, contudo, que não o pode fazer por ele. Embora se ponha em causa o vitalismo dos alunos, uma das imagens de marca do Movimento da Educação Nova, que os conduziria na descoberta dos meandros do labirinto, por meio do qual eles poderiam aceder aos instrumentos da cultura e ao desenvolvimento de competências que lhes permitirão construir-se e afirmar-se como pessoas, não se põe em causa nem o seu protagonismo nem a necessidade de se ter em conta a singularidade dos percursos a que esse mesmo protagonismo os conduz.

É urgente, por isso, que se reconheça que é o modo como, no âmbito da educação escolar, o professor investe na construção de um processo de comunicação com os seus alunos que determina a possibilidade de estes aprenderem. Constata-se, assim, de acordo com essa perspectiva, que a problemática da influência educativa deixa de ser uma problemática subentendida e restrita. Uma problemática que, como fez o Movimento da Educação Nova, ou foi iludida como uma problemática pedagógica ou, pior do que isso, foi considerada como uma questão que dizia respeito, apenas, àque- les que se identificam com o paradigma da instrução. No campo das pedagogias da comunicação, não só não se ilude a importância da problemática da influência educativa como, sobretudo, o reconhecimento desta não implica que se recuse o protagonismo dos alunos como uma condição das aprendizagens que estes deverão efectuar, ainda que tal protagonismo seja, na verdade, entendido como um coprotagonismo que se desenvolve em função de um património cultural que tanto o baliza como o potencia, deixando de se entender, nesse âmbito, o espaço de acção docente como o espaço do demiurgo ou o do parceiro que vai no lugar-do-morto (Houssaye, 1996), de forma a que a perda da centralidade pedagógica que o professor detinha no seio do paradigma da instrução possa constituir uma oportunidade de os professores passarem a assumir uma maior importância educativa, decorrente do seu contributo para a promoção activa de um processo de comunicação, entendido como condição necessária à realização das aprendizagens dos seus alunos.

Um processo que pode ser melhor compreendido em torno da noção de "momento pedagógico” que Philippe Meirieu (2002) desenvolveu, revelando-nos, por um lado, a complexidade dos desafios que se colocam a todos aqueles que não se identificam com o paradigma da instrução e demonstrando, por outro, que não é a influência educativa que importa problematizar, mas o modo como esta é exercida.

Face a um aluno que tem direito a resistir à acção dos educadores, o que tanto pode ser entendido como um acto cultural como uma manifestação de inteligência, o que interessa discutir é como é que esses educadores reconhecem, interpretam e agem perante um acto tão inevitável.

Nas abordagens pedagógicas mais conservadoras, tal manifestação de resistência deveria ser objecto de um processo de aniquilação, enquanto no campo das pedagogias da aprendizagem, pelo menos nos discursos que enformam um tal campo, a resistência teria que ser objecto de exaltação, na medida em que 
tenderia a mostrar aos educadores a direcção do caminho a seguir. Para aqueles que se situam no espaço das pedagogias da comunicação, e tendo por referência a já referida reflexão de Meirieu (2002) a partir da noção de "momento pedagógico”, a resistência do alunos a aprender não confina os professores a exercer o poder que detêm sobre eles, mas a tomar consciência da necessidade de estabelecer diálogos mais ou menos singulares com sujeitos únicos que enfrentam perplexidades originais face a objectos culturais que obrigam os professores a

[...] explorar sem tréguas os obstáculos inerentes ao seu próprio discurso, circunscrever as formulações aproximativas, buscar incansavelmente exemplos e dispositivos novos, multiplicar as reformulações inventivas. (p. 80)

São esses diálogos que se podem transformar em encontros, os quais permitam

[...] oferecer um objecto de saber de que o outro possa apoderar-se, para examiná-lo, para pegá-lo nas mãos, para manipulá-lo, para apropriar-se dele ou desvirtuá-lo, enfim, para pôr "algo de si nele". (p. 80)

Encontros esses que não são a expressão de intenções educativas colonizadoras nem poderiam resultar de qualquer processo de demissão educativa, já que só acontecem quando o professor tiver "multiplicado os 'pontos de apoio' e aberto perspectivas que constituirão os meios para o aluno exercer a sua inteligência” (p. 80).

Que influência educativa é essa? Não é certamente a influência tutelar que tipifica os discursos e as acções que têm lugar na dita es- cola tradicional, mas é certamente uma influência que se define em função quer da organização dos espaços e dos tempos educativos, quer dos instrumentos de regulação que se utilizam e que estimulam os alunos a utilizar, quer dos dispositivos de interacção relacional e curricular que se propõem. Eis-nos, assim, perante um desafio que, de algum modo, é afectado ainda tanto pela sedução que o empirismo pedagógico ainda consegue exercer no campo educativo, como, sobretudo, pela ambiguidade, pela ausência de sustentabilidade ou pela incompletude das reflexões sobre o estatuto e as especificidades epistemológicas dos saberes especializados como instrumentos pedagógicos de referência do processo de construção e legitimação dos saberes escolares. Provavelmente, e à medida que formos produzindo reflexões cada vez mais fundamentadas e coerentes, a problemática que a influência educativa constitui poderá adquirir outra visibilidade e impacto pedagógico, ainda que importe reconhecer o caminho já percorrido. Um caminho que, pelo menos, permite que entendamos os alunos como seres que, no seio das escolas, estabelecem, a partir daquilo que são e que sabem, diálogos, por vezes confrontos, com aquilo que os outros ali fisicamente presentes são e sabem. Diálogos esses, seja qual for a forma que possam assumir, que se desenvolvem num dado ambiente cultural e tendo por referência o património que outros, que ali se encontram fisicamente ausentes, lhes legaram para que, assim, o que eles já são e já sabem possa adquirir uma outra amplitude e coerência, de forma a que os referidos diálogos possam constituir, enfim, momentos necessários ao seu processo de construção e de afirmação como pessoas. 


\section{Referências bibliograficas}

ALTET, M. As pedagogias da aprendizagem. Lisboa: Instituto Piaget, 1999.

BÖHM, W. Maria Montessori. In: HOUSSAYE, J. (Org.). Quinze pedagogues: leur influence aujourd'hui. Paris: Armand Colin, 1996. p. $149-166$.

BRUNER, J. S. Actos de significado: para uma psicologia cultural. Lisboa: Edições 70, 1990.

Cultura da educação. Lisboa: Edições 70, 2000.

Realidade mental, mundos possíveis. Porto Alegre: Artmed, 2002.

CLAPAREDE, E. L'éducation fonctionelle. Neuchatel: Delachaux \& Niestlé, 1931.

A escola sob medida. Rio de Janeiro: Fundo de Cultura, 1959.

Psychologie de l'enfant et pédagogie expérimentale I: le développment mental. Neuchatel: Delachaux \& Niestlé, 1972.

COSME, A. Ser professor numa escola e num tempo de incertezas: desafios, exigências e dilemas profissionais. 2006. Tese (Doutorado)- Faculdade de Psicologia e de Ciências da Educação da Universidade do Porto, Porto, 2006. (Documento policopiado).

COUSINET, R. Une méthode de travail libre par groupes. Paris: Les Éditions du Cerf, 1945.

Pédagogie de l'apprentissage. Paris: PUF, 1959.

A educação nova. Lisboa: Moraes, 1978.

DANIELS, H. Vygotsky e a pedagogia. São Paulo: Loyola, 2003.

DECROLY, O. La function de globalisation et l'enseignement. Bruxelles: Desoer, 1965.

DECROLY, O.; HAMAIIDE, A. Le calcul et la mesure au premier degré de l'école Decroly. Neuchâtel: Delachaux \& Niestlé, 1932.

DELEDALLE, G. John Dewey. Paris: PUF, 1995.

DEWEY, J. Experience and education. New York: Macmillan, 1963.

Democracy and education. New York: Macmillan, 1966.

A escola e a sociedade: a criança e o currículo. Lisboa: Relógio d’Água, 2002.

DOTTRENS, R. Educar e instruir I. Lisboa: Estampa, 1974.

Educar e instruir II. Lisboa: Estampa, 1974a.

Educar e Instruir III. Lisboa: Estampa, 1974b.

DUBREUCQ, F. Jean-Ovyde Decroly (1871-1932). In: MORSY, Z. (Coord.). Penseurs de l'éducation. Paris: Éditions UNESCO (Révue trimestrielle de l'éducation), 1994. p. 161-173.

ESTRELA, A. 0 Movimento da Escola Moderna e a formação de professores. In: VILHENA, G.; SOARES, J.; HENRIQUE, M. (Orgs.). Nos 25 anos do Movimento da Escola Moderna Portuguesa, 1992. p. 19-23

FERNANDES, R. E. T. Escola e influência educativa: 0 estatuto dos discursos didácticos inovadores no $1^{\circ}$ Ciclo do Ensino Básico em Portugal. 2003. Tese (Doutorado)- Faculdade de Psicologia e de Ciências da Educação da Universidade do Porto, Porto (Documento policopiado), 2003.

FERRIĖRE, A. A escola activa. Porto: Editora Educação Nacional, 1934. 
HAMAÏDE, A. La méthode Décroly. Neuchatel: Delachaux \& Niestlé, 1932.

HAMELINE, D. Adolphe Ferrière. In: HOUSSAYE, J. (Org.). Quinze pédagogues: leur influence aujourd'hui. Paris: Armand Colin, 1994. p. 181-195.

Édouard Claparède. In: HOUSSAYE, J. (Org.). Quinze pédagogues: leur influence aujourd'hui. Paris: Armand Colin, 1994a. p. $161-173$

HAMELINE, D.; JORNOD, A.; BELKAID, M. L'école active: textes fondateurs. Paris: PUF, 1995.

HOUSSAYE, J. Le triangle pédagogique ou comment compreendre la situation pédagogique. In: HOUSSAYE, J. (Dir.). La pédagogie: une encyclopédie pour aujourd'hui. Paris: ESF, 1996. p. 13-24.

KILPATRICK, W. 0 método de projecto. Mangualde: Pedago, 2006.

MEIRIEU, P. A pedagogia entre o Dizer e o Fazer. Porto Alegre: Artmed, 2002.

MONTESSORI, M. A criança. Lisboa: Portugália, [s.d.].

Pédagogie scientifique: la découverte de l'enfant. Paris: Desclée de Brouwer, 1958.

NIZA, S. 0 modelo curricular da educação pré-escolar da Escola Moderna Portuguesa. In: FORMOSINHO, J. O. (Org.). Modelos curriculares para a educação de infância. Porto: Porto Editora, 1996. p. 139-159.

A organização social do trabalho de aprendizagem no $1^{0}$ Ciclo do Ensino Básico. Inovação, v. 11, p. 77- 98, 1998.

NÓVOA, A. Comunicação do representante da sociedade portuguesa de Ciências da Educação. In: VILHENA, G.; SOARES, J.; HENRIQUE, M. (Orgs.). Nos 25 anos do Movimento da Escola Moderna Portuguesa, 1992. p. 25-26.

OURY, F.; VASQUEZ, A. Da classe cooperativa à pedagogia institucional I. Lisboa: Estampa, 1977.

Da classe cooperativa à pedagogia institucional II. Lisboa: Estampa, 1977a.

Da classe cooperativa à pedagogia institucional III. Lisboa: Estampa, 1977b.

Da classe cooperativa à pedagogia institucional IV. Lisboa: Estampa, 1977c.

Da classe cooperativa à pedagogia institucional V. Lisboa: Estampa, 1978.

Vers une pedagogie institutionelle? Vigneux: Matrice, 1988.

PARKHURST, H. Education on the Dalton Plan. Whitefish: Kessinger Publishing, 1922.

PONTECORVO, C. et al. Discutindo se aprende: interacção social, conhecimento e escola. Porto Alegre: Artmed, 2005.

ROCHA, F. Correntes pedagógicas contemporâneas. Aveiro: Estante, 1988. Colecção Ciências da Educação e Desenvolvimento Humano.

ROGOFF, B. A natureza cultural do desenvolvimento humano. Porto Alegre: Artmed, 2005.

ROLDÃO, M. C. 0 pensamento concreto da criança: uma perspectiva do currículo a questionar. Lisboa: Instituto de Inovação Educacional, 1994.

SOETÄRD, M. Jean-Jacques Rousseau. In: HOUSSAYE, J. (Org.). Quinze pedagogues: leur influence aujourd'hui. Paris: Armand Colin, 1994. p. 23-36.

WASHBURNE, C. La escuela individualizada. Madrid: Pi y Margall, 1934.

VYGOTSKY, L. S. Mind in society: the development of higher psychological processes. Cambridge: Harvard University Press, 1978. 
Pensamento e linguagem. São Paulo: Martins Fontes, 1987.

A formação social da mente. São Paulo: Martins Fontes, 1998.

Recebido em 17.11 .08

Aprovado em 05.05.08

Rui Trindade é professor do Grupo de Ciências da Educação da Faculdade de Psicologia e de Ciências da Educação da Universidade do Porto, onde integra, como investigador, o Centro de Investigação e Intervenção Educativas (CIIE). Doutor em Ciências da Educação, desenvolve trabalho como docente e no domínio da pesquisa na área dos Estudos sobre Aprendizagem, Organização e Gestão do Trabalho Pedagógico e Pedagogia no Ensino Superior. 